\title{
ANALISA PENGARUH PERCEIVED EASE OF USE TERHADAP BEHAVIOR INTENTION MELALUI PERCEIVED USEFULNESS SEBAGAI MEDIA INTERVENING PADA DIGITAL PAYMENT OVO
}

\author{
Michaela Louisa Muliadi ${ }^{*}$, Edwin Japarianto ${ }^{1}$ \\ ${ }^{1}$ Fakultas Bisnis dan Ekonomi, Universitas Kristen Petra \\ Jl. Siwalankerto 121-131, Surabaya 60236 \\ * Penulis korespondensi; Email: m36416014@petra.ac.id; edwinj@petra.ac.id
}

\begin{abstract}
Abstrak: Kemajuan teknologi serta informasi membuat segala sesuatu menjadi lebih mudah untuk dilakukan sehingga menyebabkan adanya perubahan gaya hidup masyarakat. Salah satu penerapan perkembangan teknologi yang terjadi di Indonesia yaitu munculnya perusahaan FinTech (financial technology) yang telah menciptakan metode pembayaran baru yaitu melalui E-Wallet. Penelitian ini bertujuan untuk menganalisis pengaruh dari perceived ease of use terhadap behavior intention dengan perceived usefulness sebagai variabel intervening pada $E$-Wallet OVO. Hasil dari penelitian ini membuktikkan bahwa kemudahan serta manfaat yang dirasakan individu dalam menggunakan teknologi informasi akan memicu timbulnya niat individu untuk menggunakan teknologi informasi tersebut.
\end{abstract}

Kata kunci: Perceived ease of use; perceived usefulness; behavior intention.

\begin{abstract}
The advance growth of technology and information makes everything become easier which causes changes in people's lifestyle. One of the applications on technology development that occurred in Indonesia is financial technology company (fintech) which created a new payment method that can be done through E-Wallet. This study aims to analyze the effect of perceived ease of use towards behavior intention with perceived usefulness as an intervening variable from OVO digital payment. This study shows that the ease of use and the usefulness of information technology will encourage people to have the intention to use the information technology.
\end{abstract}

Keywords: Perceived ease of use; perceived usefulness; behavior intention.

\section{PENDAHULUAN}

Perkembangan teknologi yang semakin canggih tanpa disadari menyebabkan adanya perubahan kebiasaan dan gaya hidup masyarakat di seluruh dunia. Perkembangan teknologi yang semakin modern membuat hidup manusia menjadi lebih mudah dimana semua dapat dilakukan tanpa memerlukan usaha yang besar. Semua pekerjaan dapat dilakukan hanya dengan bermodal smartphone melalui pemanfaatan aplikasi yang tersedia, berbagai macam layanan dapat kita nikmati dimanapun dan kapanpun kita mau.

Salah satu penerapan perkembangan teknologi yang terjadi di Indonesia yaitu munculnya perusahaan FinTech (Financial Technology) yang menciptakan metode pembayaran baru yaitu melalui $E$-Wallet. Hal ini sangat berpengaruh terhadap perkembangan sistem pembayaran dalam masyarakat melakukan transaksi sehari-hari. Dalam prakteknya, transaksi menggunakan $E$-Wallet didukung dengan adanya jaringan internet dan juga aplikasi yang dapat diunduh di smartphone sehingga konsumen dapat dengan mudah menggunakannya dimanapun dan kapanpun mereka butuhkan.

Salah satu aplikasi $E$-Wallet yang sangat populer di Indonesia yaitu OVO. E-Wallet OVO merupakan salah satu dompet digital yang berupa aplikasi yang menawarkan layanan pembayaran serta transaksi secara online yang telah diakui secara sah oleh Bank Indonesia.

Kepraktisan E-Wallet OVO menyebabkan pengguna OVO tidak perlu khawatir jika tidak membawa uang tunai ketika berpergian. Hal tersebut didukung dengan kemudahan yang dirasakan masyarakat dalam melakukan Top Up saldo OVO. Berdasarkan hasil survey yang telah dilakukan, sebesar $77 \%$ dari masyarakat Indonesia lebih menyukai gaya hidup cashless dimana semua transaksi pembelian dapat dilakukan menggunakan smartphone melalui mobile payment (Indiana Malia, 2019).

Kepraktisan yang dirasakan oleh responden juga didukung oleh kerjasama OVO dengan banyak merchant sehingga pengguna OVO dapat melakukan transaksi menggunakan OVO hampir di seluruh tempat yang ada di Indonesia. Selain itu, OVO juga bekerja sama dengan berbagai perusahaan besar seperti Grab dan Tokopedia yang tentunya memudahkan pengguna OVO untuk melakukan transaksi untuk kebutuhan sehari-hari mereka seperti membeli pulsa.

Berdasarkan penelitian sebelumnya, perceived ease of use (kemudahan yang dirasakan user) dan perceived usefulness (manfaat yang dirasakan user) 
terbukti memiliki pengaruh terhadap keinginan masyarakat menggunakan sesuatu. Dengan adanya kemudahan dan manfaat yang dirasakan, seseorang akan terdorong untuk menggunakan suatu teknologi atau sistem.

Perceived usefulness memiliki influences lebih yang besar terhadap behavior intentions daripada perceived ease of use (Wu \& Chen, 2017). Penelitian yang telah dilakukan oleh Bing Wu dan Chen menggunakan pembelajaran online sebagai objek penelitian mereka dimana perceived usefulness merupakan mediasi dari perceived ease of use yang tentunya sangat menentukan akan keberlanjutan niat masyarakat dalam menggunakan pembelajaran online. Penelitian tersebut menunjukan bahwa responden tidak keberatan jika mereka harus mengeluarkan upaya lebih untuk menggunakan pembembelajaran online jika mereka merasa bahwa hal tersebut bermanfaat bagi mereka.

Namun, tidak menutup kemungkinan bila perceived ease of use lebih berpengaruh secara signifikan terhadap behavior intentions karena perbedaan objek yang diteliti (Bonn et al., 2016; Danurdoro \& Wulandari, 2016). Beberapa penelitian yang telah dilakukan sebelumnya dengan berbagai objek penelitian seperti internet banking, kartu kredit dan online shopping; menyatakan bahwa kemudahan yang dirasakan seseorang dalam menggunakan sesuatu akan menjadi faktor pendorong untuk kembali menggunakan di kemudian hari. Hal tersebut didasari pada kebiasaan masyarakat yang menyukai segala hal yang instan, fleksibel dan sederhana.

Berdasar Fenomena di atas peneltian ini bertujuan untuk mengetahui pengaruh perceived ease of use terhadap behavior intention masyarakat Surabaya dalam menggunakan OVO

\section{LANDASAN TEORI}

\section{E-Wallet}

E-Wallet (Electronic Wallet) merupakan suatu sistem teknologi informasi sejenis internet perbankan yang dilengkapi dengan berbagai macam fitur yang memungkinkan individu untuk melakukan transaksi hanya dengan menggunakan aplikasi yang dapat dengan mudah diunduh di smartphone. Aplikasi $E$ Wallet memungkinkan individu untuk menyimpan, memantau, serta mengontrol daftar belanja mereka (Salah Uddin \& Yesmin Akhi, 2014). Hadirnya EWallet menyebabkan berubahnya kebiasaan masyarakat dari yang menggunakan uang tunai untuk bertransaksi beralih menjadi pengguna non-tunai.

\section{Perceived Ease of Use}

Perceived Ease of Use merupakan tingkat kepercayaan individu bahwa penggunaan suatu sistem teknologi informasi secara aktual dapat terbebas dari usaha serta dapat meringankan dan memudahkan pekerjaan (Davis, 1989; Indarsin \& Ali, 2017). Seiring perkembangan zaman, masyarakat lebih menyukai sesuatu yang simple dan mudah dalam penggunaan sehingga tidak memerlukan usaha yang besar yang tentunya akan menghambat produktivitas. Perceived Ease Of Use merupakan salah satu elemen penting yang diperlukan oleh teknologi (Moslehpour et al., 2018).

\section{Dimensi Perceived Ease of Use}

Menurut Davis (1989), dimensi dari Perceived Ease of Use dibagi menjadi beberapa bagian yang terdiri dari:

1. easy to learn

2. controllable

3. clear and understandable

4. Flexible

5. easy to become skillful

6. easy to use

\section{Perceived Usefulness}

Perceived Usefulness dapat didefinisikan sebagai sejauh mana individu merasa bahwa dengan menggunakan teknologi informasi mereka merasa adanya keuntungan yang didapat, selain itu kinerja dan produktivitas pengguna teknologi informasi akan meningkat karena pekerjaan dapat diselesaikan dengan waktu yang lebih singkat (Davis, 1989; Moslehpour et al., 2018). Manfaat yang dirasakan individu dalam penggunaan teknologi informasi dapat mengubah perilaku individu (Moslehpour et al., 2018).

\section{Dimensi Perceived Usefulness}

Dimensi dari Perceived Usefulness dibagi menjadi beberapa bagian yang terdiri dari:

1. Work more quickly

2. Increase productivity

3. Usefull

\section{Behavior Intentions}

Niat perilaku (behavior intention) merupakan kecenderungan individu untuk bersedia melakukan suatu aktivitas terhadap suatu produk maupun perusahaan (Engel, J. F., Blackwell, R. D., \& Miniard, 1995). Menurut Kbbi (n.d.), niat merupakan kehendak atau keinginan dalam hati seseorang. Zeithaml, V.A., Berry, L.L., Parasuraman, (1996) mengemukakan bahwa niat perilaku dapat mencerminkan keinginan 
individu untuk melakukan suatu aksi serta merekomendasikan suatu objek kepada orang lain. Niat perilaku merupakan penentu aksi aktual individu (Kuo, Y. F., 2009). Dengan melakukan pengukuran niat perilaku yang benar, perilaku aktual individu dapat dengan mudah diprediksi secara akurat (Ajzen, I., \& Fishbein, 2005).

\section{Dimensi Behavior Intentions}

Behavior intention memiliki empat dimensi antara lain:
1. Motivation to use
2. Repeat to use
3. Recommend to other
4. Positive Remarks

\section{Hubungan Antar Konsep dan Hipotesis Penelitian}

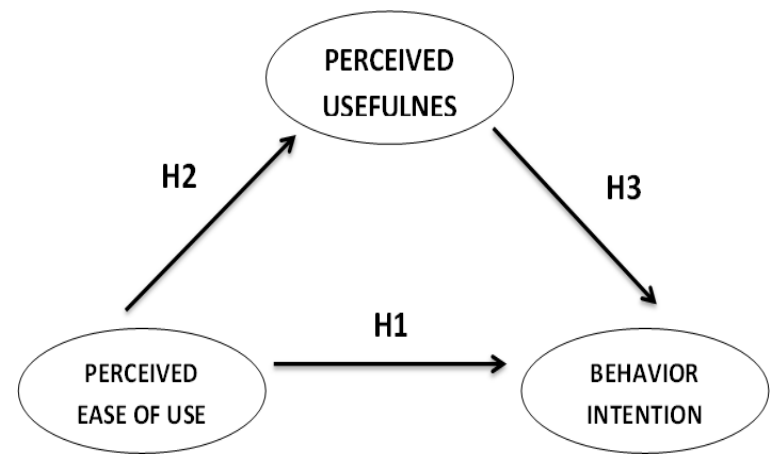

Gambar 1. Kerangka Konseptual

1. Pengaruh Perceived Ease of Use terhadap Behavior Intention

Perceived ease of use berpengaruh secara signifikan terhadap Behavior intention (Davis, 1989; Nikou \& Economides, 2017). Perceived ease of use terbukti berpengaruh secara positif terhadap niat perilaku individu. Kemudahan yang dirasakan individu dalam penggunaan sesuatu akan mendorong munculnya niat individu untuk bersedia menggunakannya karena masyarakat cenderung menyukai sesuatu yang simple dan mudah sehingga tidak memerlukan usaha yang besar dalam penggunaannya.

H1: Perceived ease of use memberikan pengaruh terhadap behavior intention.

2. Pengaruh Perceived Ease of Use terhadap Perceived Usefulness

Berdasarkan penelitian yang telah dilakukan oleh Abdullah \& Ward, 2016; Nikou \& Economides, 2017; Wu \& Chen, 2017; Perceived ease of use terbukti memiliki pengaruh positif pada perceived usefulness. Kemudahan yang dirasakan individu berpengaruh secara signifikan terhadap manfaat yang didapat oleh individu. Kemudahan yang dirasakan individu dalam menggunakan teknologi informasi menyebabkan adanya manfaat yang dapat dirasakan oleh individu.

H2: Perceived ease of use memberikan pengaruh terhadap perceived usefulness

3. Pengaruh Perceived Usefulness terhadap Behavior Intention

Berdasarkan penelitian yang dilakukan oleh Nikou \& Economides (2017) perceived usefulness terbukti berpengaruh secara positif terhadap niat perilaku individu (behavior intention). Manfaat yang dirasakan individu dalam menggunakan sesuatu dapat mendorong munculnya niat individu untuk bersedia menggunakannya. Manfaat yang dirasakan pengguna dapat berupa peningkatan produktivitas dan efisiensi individu maupun keuntungan baik dari segi finansial maupun non-finansial sehingga individu memiliki keinginan untuk menggunakan suatu teknologi informasi.

H3: Perceived usefulness memberikan pengaruh terhadap behavior intention

\section{METODE PENELITIAN}

\section{Populasi dan Sampel}

Menurut Sugiyono (2011), populasi merupakan suatu wilayah yang terdiri atas subjek maupun objek yang memiliki karakteristik tertentu yang diterapkan oleh penulis atau peneliti untuk dipelajari lebih lanjut hingga kemudian dapat menghasilkan suatu pernyataan kesimpulan. Populasi dalam penelitian ini merupakan masyarakat Surabaya yang menggunakan aplikasi E-Wallet OVO.

Jenis teknik non probability sampling yang digunakan dalam penelitian ini yaitu purposive sampling dimana penulis akan melakukan penilaian untuk memilih sampel yang sesuai dengan tujuan untuk mendapatkan responden yang paling sesuai dengan kriteria tertentu. Adapun kriteria yang dimaksud adalah:

1. Masyarakat Surabaya (terutama generasi $Y$ dan Z)

2. Bertransaksi menggunakan E-Wallet OVO minimal $3 x$ dalam 2 bulan terakhir.

3. Melakukan top up minimal Rp. $100.000,00$

Dalam menentukan jumlah ukuran minimum sampel, penulis menggunakan rumusan Cochran dengan harapan jumlah minimum tersebut dapat mewakili populasi penelitian.

$$
\begin{gathered}
n=\frac{Z^{2} p(1-p)}{\left(e^{2}\right)} \\
n=\frac{(1,96)^{2} 0,5(1-0,5)}{\left(0,1^{2}\right)}
\end{gathered}
$$




$$
\begin{aligned}
n=\frac{3,8416(0,25)}{(0,01)} \\
n=96,04 \rightarrow \text { dibulatkan menjadi } 100
\end{aligned}
$$

\section{Definisi Operasional Variabel}

\section{Perceived Ease of Use (X1)}

Perceived ease of use adalah persepsi konsumen dalam menggunakan E-Wallet OVO secara aktual individu dapat merasakan adanya kemudahan serta usaha yang minimal. Berikut ini merupakan dimensi serta indikator dari perceived ease of use:

\section{a. Easy to learn}

Merupakan kemudahan yang dirasakan dalam mempelajari cara penggunaan E-Wallet OVO.

b. Controllable

Merupakan kemudahan yang dirasakan dalam mendapatkan apa yang mereka inginkan dalam menggunakan $E$-Wallet $\mathrm{OVO}$.

c. Clear and understandable

Merupakan kejelasan dari segi tampilan, fitur, serta cara pengoprasian $E$-Wallet $\mathrm{OVO}$

d. Flexible

E-Wallet OVO karena dapat digunakan dimanapun dan kapanpun mereka butuhkan.

e. Easy to become skillful

Kemudahan dalam menguasai cara mengoperasikan $E$-Wallet OVO.

f. Easy to use

kemudahan yang dirasakan individudalam menggunakan $E$-Wallet OVO.

\section{Perceived Usefulness (Y1)}

\section{a. Work more quickly}

Keadaan dimana pekerjaan seseorang dapat diselesaikan dengan lebih cepat karena menggunakan E-Wallet OVO.

b. Increase productivity

Produktivitas individu mengalami peningkatan karena menggunakan E-Wallet OVO.

c. Useful

Individu merasakan adanya manfaat yang mereka dapat karena menggunakan E-Wallet OVO.

\section{Behavior Intention (Z1)}

a. Motivation to use

Adanya dorongan dari dalam diri individu untuk menggunakan E-Wallet OVO.

b. Repeat to use Individu bersedia untuk menggunakan $E$-Wallet OVO untuk bertransaksi secara berulang kali.

c. Recommend to other

Individu bersedia dan memiliki keinginan untuk merekomendasikan orang lain untuk menggunakan E-Wallet OVO.

\section{d. Positive Remarks}

Individu memberikan komentar serta reaksi yang positif terhadap E-Wallet OVO.

\section{Teknik Analisis Data}

Analisis data dalam penelitian ini didasarkan pada data yang diperoleh dari instrumen penelitian yang berupa hasil kuesioner yang disebarkan penulis dan kemudian diolah dengan metode statistik.

\section{Path Analysis}

Model Path Analysis menggunakan metode Partial Least Square (PLS) sebagai metode pengujian statistik dimana PLS merupakan bagian dari Structural Equation Marketing (SEM). PLS dapat digunakan untuk mengetahui kompleksitas hubungan antar variabel serta hubungan antara suatu variabel dengan masing-masing indikatornya. Dengan menggunakan PLS, penulis mampu menangani model yang kompleks dengan multiple variabel independen dan dependen dengan banyak indikator, dapat digunakan pada sampel dalam jumlah kecil, serta data distribusi yang condong (Abdillah, W., \& Hartono, 2015).

\section{ANALISA DAN PEMBAHASAN}

\section{Path Analysis}

\section{Model Fit}

Penelitian ini memiliki nilai RMS Theta sebesar 0,161 dan nilai Chi Square sebesar 234,346. Jika nilai Chi square dibagi dengan jumlah sampel penelitian yaitu sebesar 100 responden maka diperoleh nilai sebesar 2,34346 yang berarti bahwa penelitian ini dapat dinyatakan reliable dan valid tetapi bukan sebagai exploratory melainkan hanya sebagai confirmatory.

Nilai $\mathrm{P}$ value pada hubungan antara perceived ease of use terhadap behavior intention menunjukkan angka sebesar 0,011 , perceived ease of use terhadap perceived usefulness sebesar 0,000 , dan perceived usefulness terhadap behavior intention sebesar 0,016. Secara keseluruhan, penelitian ini dapat dinyatakan baik karena seluruh hubungan dalam penelitian ini memiliki nilai $\mathrm{P}$ Value dibawah angka 0,05 .

\section{Path Coefficient, Coefficient of Determination $\left(\mathbf{R}^{2}\right)$ dan Prediction Relevance $\left(\mathbf{Q}^{2}\right)$}

Pada analisis path coefficient ini, dapat dilihat bahwa perceived usefulness merupakan variabel intervening yang memberikan dampak positif dalam membentuk behavior intention. Pada gambar 2 jelas terlihat bahwa nilai path coefficient terbesar merupakan hubungan antara perceived ease of use terhadap 
perceived usefulness dengan nilai sebesar 0,721. Sedangkan path coefficient variabel perceived ease of use terhadap behavior intention memiliki nilai sebesar 0,325. Perceived usefulness sebagai variabel intervening dalam penelitian ini memiliki pengaruh yang positif terhadap behavior intention sebagai variabel dependen. Perceived usefulness memiliki nilai path coefficient sebesar 0,307 terhadap behavior intention.

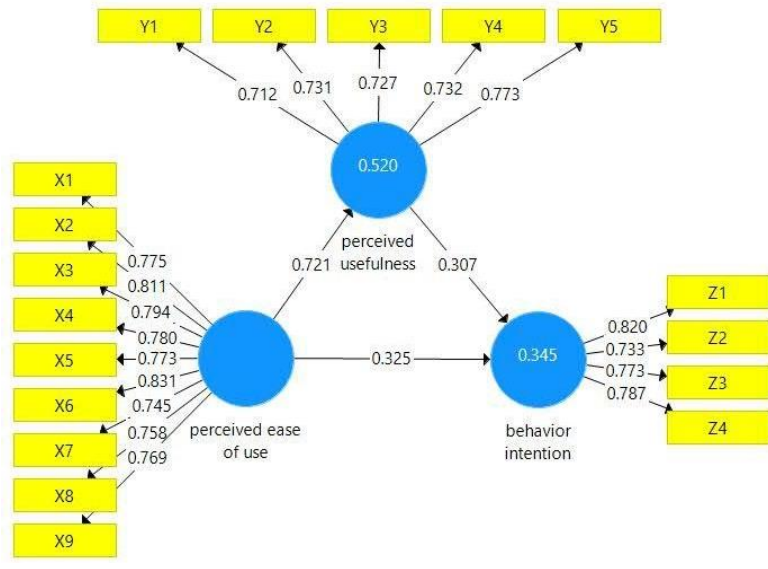

Gambar 2. Path Coefficient dan Coefficient of Determination

Dari gambar diatas dapat dilihat bahwa seluruh variabel dalam penelitian ini memiliki nilai path coefficient yang positif. Semakin tinggi nilai path coefficient antar variabel maka semakin kuat hubungan serta pengaruh yang diberikan variabel tersebut terhadap suatu variabel.

Nilai coefficient of determination (R2) dapat diketahui dengan melihat angka yang berada di dalam lingkaran pada variabel penelitian. Dari gambar 2 dapat dilihat bahwa variabel perceived ease of use menjelaskan variabel perceived usefulness sebanyak $52 \%$ dengan nilai varian sebesar 0,520 yang artinya sebesar $48 \%$ lainnya dijelaskan oleh variabel lain diluar penelitian ini. Variabel behavior intention dipengaruhi oleh variabel perceived ease of use dan perceived usefulness dengan nilai varian sebesar 0,345 . Dari penelitian ini dapat diketahui bahwa perceived ease of use dan perceived usefulness mempengaruhi behavior intention sebesar 34,5\% dimana sebesar $65,5 \%$ lainnya, behavior intention dapat terbentuk melalui variabel - variabel lain di luar penelitian ini. Nilai predictive relevance dapat diperoleh dengan menggunakan rumus:

$$
\begin{gathered}
\mathrm{Q} 2=1-(1-\mathrm{R} 12) \ldots .(1-\mathrm{Rp} 2) \\
\mathrm{Q} 2=1-(1-0,520)(1-0,345) \\
\mathrm{Q} 2=0,686
\end{gathered}
$$

Dari hasil perhitungan predictive relevance diatas diperoleh nilai sebesar $0,686(>0)$ yang artinya sebesar $68,6 \%$ dijelaskan oleh variabel dalam penelitian ini yaitu perceived ease of use, perceived usefulness, dan behavior intention. Sebesar 31,4\% dijelaskan oleh faktor lain diluar penelitian ini. Berdasarkan perhitungan tersebut, model penelitian ini dapat dikatakan layak memiliki nilai prediktif relevan.

\section{T-statistics dan Uji Hipotesis}

Nilai T-Statistics dapat diperoleh melalui prosedur bootstrapping. Nilai T-Statistics berguna untuk menarik Nilai T-Statistic pada hubungan antara perceived ease of use terhadap behavior intention menunjukkan angka sebesar 2,478 yang artinya perceived ease of use memiliki pengaruh yang signifikan terhadap behavior intention. T-Statistic pada pengaruh perceived ease of use terhadap perceived usefulness menunjukkan angka 12,880 yang artinya perceived ease of use berpengaruh secara signifikan terhadap perceived usefulness. Nilai T-Statistic pada hubungan antara perceived usefulness terhadap behavior intention menunjukkan angka sebesar 2,247 yang artinya terdapat pengaruh yang signifikan pada hubungan antara perceived usefulness terhadap

\begin{tabular}{|c|c|c|}
\hline Hipotesis & Keterangan & T-Statistics \\
\hline $\mathrm{H}_{1}$ & $\begin{array}{l}\text { Terdapat pengaruh dari } \\
\text { Perceived Ease Of Use } \\
\text { terhadap Behavior Intention }\end{array}$ & 2,478 \\
\hline $\mathrm{H}_{2}$ & $\begin{array}{l}\text { Terdapat pengaruh dari } \\
\text { Perceived Ease Of Use } \\
\text { terhadap Perceived } \\
\text { Usefulness }\end{array}$ & 12,880 \\
\hline $\mathrm{H}_{3}$ & $\begin{array}{l}\text { Terdapat pengaruh dari } \\
\text { Perceived Usefulness } \\
\text { terhadap Behavior Intention }\end{array}$ & 2,247 \\
\hline
\end{tabular}
behavior intention.

Tabel 1. Kesimpulan Uji Hipotesis

Berdasar table 1. Dapat di Tarik kesimpulan:

1. Pengaruh Perceived Ease of Use terhadap Behavior Intention memiliki nilai T-Statistic 2,478 dimana artinya terdapat pengaruh dari Perceived Ease of Use terhadap Behavior Intention.

2. Pengaruh Perceived Ease of Use terhadap Perceived Usefulness memiliki nilai T-Statistic 12,880 dimana artinya terdapat pengaruh dari Perceived Ease of Use terhadap Perceived Usefulness.

3. Pengaruh Perceived Usefulness terhadap Behavior Intention memiliki nilai T-Statistic 2,247 dimana artinya terdapat pengaruh dari Perceived Usefulness terhadap Behavior Intention. 


\section{Pembahasan}

\section{Perceived Ease of Use terhadap Behavior Intention}

Penelitian ini menunjukkan bahwa variabel perceived ease of use dari $E$-Wallet OVO memiliki pengaruh terhadap behavior intention

Hasil dari penelitian ini sesuai dengan pendapat Hansen et al., (2018) bahwa perceived ease of use berpengaruh secara signifikan terhadap behavior intention karena bila sesuatu dirasa individu lebih mudah untuk digunakan maka mereka akan terdorong untuk memiliki niat untuk menggunakannya karena mereka tidak perlu bersusah payah melakukan sesuatu dengan usaha yang besar. Selain itu, hubungan antara perceived ease of use dengan behavior intention telah terbukti memiliki validitas yang tinggi karena sudah banyak diaplikasikan pada berbagai industri teknologi seperti yang diterapkan pada proses pembelajaran online, telekonferensi, dan berbagai industri teknologi lainnya (Cheung, R., Vogel, 2013; Park et al., 2014).

Masyarakat menyukai segala sesuatu yang instan serta tidak memerlukan usaha yang besar dalam melakukannya. Seiring perkembangan zaman, budaya cashless telah menjadi karakteristik dan kebiasaan sebagian orang. Berdasarkan pengamatan lapangan yang telah dilakukan peneliti terhadap sekitarnya, sebanyak 7 dari 10 orang memiliki kebiasaan cashless dimana mereka akan memanfaatkan dan menggunakan platform pembayaran online baik itu melalui transfer $m$-banking maupun menggunakan dompet digital. E-Wallet OVO hadir sebagai solusi bagi masyarakat yang terbiasa bertransaksi secara cashless. Masyarakat dapat dengan mudah menggunakan aplikasi OVO yang ada di smartphone mereka untuk bertransaksi baik untuk berbelanja online maupun offline dimanapun dan kapanpun mereka inginkan.

\section{Perceived Ease of Use terhadap Perceived Useful- ness}

Penelitian ini juga menunjukkan bahwa variabel perceived ease of use dari $E$-Wallet OVO memiliki pengaruh terhadap perceived usefulness.

Pernyataan tersebut sesuai dengan pendapat Abdullah \& Ward, (2016); Marzuki et al., (2016) bahwa perceived ease of use berpengaruh secara signifikan terhadap perceived usefulness. Perceived ease of use terbukti memiliki pengaruh yang signifikan terhadap perceived usefulness karena telah diterapkan pada berbagai macam industri teknologi seperti $e$ portfolio (Abdullah et al., 2016) dan media sosial (Lee et al., 2013). Kemudahan yang dirasakan seseorang akan memberikan dampak terhadap manfaat yang akan diperoleh orang tersebut.
Kemudahan yang dirasakan masyarakat dalam menggunakan E-Wallet OVO akan menyebabkan adanya manfaat yang secara nyata dapat mereka rasakan. Berbagai macam fitur yang disediakan $E$ Wallet OVO seperti fitur untuk membayar pulsa, listrik, dan BPJS tentunya sangat memudahkan masyarakat dalam membayar kebutuhan sehari - hari mereka serta dapat menghemat waktu sehingga masyarakat dapat menjadi lebih produktif. Kemudahan yang dirasakan masyarakat dalam bertransaksi menggunakan E-Wallet OVO dapat mendorong peningkatan produktivitas, efisiensi, serta dapat mempersingkat waktu yang diperlukan untuk menyelesaikan suatu pekerjaan. OVO, pembayaran dapat diselesaikan hanya dengan bermodal smartphone dan beberapa kali click yang membutuhkan waktu tidak lebih dari 2 menit.

\section{Perceived Usefulness terhadap Behavior Intention}

Perceived usefulness dari E-Wallet OVO berpengaruh positif terhadap behavior intention. Hasil dari penelitian ini sesuai dengan pendapat Lau et al., (2019); Lim et al., (2016) bahwa perceived usefulness dapat mendorong munculnya niat individu untuk menggunakan sesuatu. Individu akan cenderung mengadopsi suatu metode pembayaran baru apabila ada nilai tambah yang dapat mereka terima (Lau et al., 2019). Berdasarkan pernyataan tersebut dapat disimpulkan bahwa perceived usefulness merupakan salah satu faktor penentu yang penting yang mendorong munculnya niat individu untuk menggunakan sesuatu.

Hubungan antara perceived usefulness dengan behavior intention pada E-Wallet OVO dapat terjadi karena $E$-Wallet OVO memberikan berbagai macam manfaat baik dari segi finansial maupun non finansial kepada penggunanya. Niat individu untuk menggunakan E-Wallet OVO dapat muncul karena mereka merasakan manfaat dari penggunaan $E$-Wallet $\mathrm{OVO}$

Banyaknya fitur pembayaran yang disediakan $E$ Wallet OVO untuk membayar berbagai macam kebutuhan sehari-hari masyarakat juga dapat mendorong masyarakat memiliki niat untuk bertransaksi menggunakan E-Wallet OVO karena dapat menghemat waktu mereka. E-Wallet OVO juga menyediakan fitur transfer antar sesama OVO maupun ke rekening bank dengan biaya yang rendah sehingga masyarakat memiliki niat untuk menggunakan $E$ Wallet OVO karena produktivitas mereka meningkat. Keuntungan tersebut tentunya mendorong munculnya niat untuk menggunakan E-Wallet $\mathrm{OVO}$. 


\section{KESIMPULAN DAN SARAN}

\section{Kesimpulan}

Berdasarkan hasil penelitian dapat dilihat perceived ease of use berpengaruh significant terhadap behavior intention melalui perceived usefulness sebagai media intervening pada digital payment $\mathrm{OVO}$ Apabila individu merasakan kemudahan dalam penggunaan sesuatu maka individu akan memiliki niat untuk menggunakan.

Kemudahan dalam penggunaan sesuatu akan menghasilkan adanya manfaat yang dapat dirasakan individu. Ketika individu merasakan adanya manfaat dan keuntungan yang mereka dapat dalam penggunaan E-Wallet OVO maka akan mendorong munculnya niat individu untuk menggunakan E-Wallet OVO untuk bertransaksi.

Dari hasil penelitian dan pembahasan yang telah dijabarkan, peneliti ingin mengajukan saran agar OVO Memperluas kerjasama dengan toko Untuk meningkatkan intensitas masyarakat menggunakan OVO agar masyarakat dapat lebih fleksibel untuk menggunakan E-Wallet OVO dimanapun mereka butuhkan.

Menambah fitur pembayaran sehingga mendorong masyarakat untuk memaksimalkan penggunaan OVO, E - Wallet OVO yang tentunya akan sangat mempermudah masyarakat dalam melakukan pembayaran.

\section{DAFTAR PUSTAKA}

Abdillah, W., \& Hartono, J. (2015). Partial Least Square (PLS) - Alternatif Structural Equation Modeling (SEM) dalam Penelitian Bisnis (cetakan 1). Andy.

Abdullah, F., \& Ward, R. (2016). Developing a General Extended Technology Acceptance Model for E-Learning (GETAMEL) by analysing commonly used external factors. Computers in Human Behavior, 56, 238-256. https://doi. org/10.1016/j.chb.2015.11.036

Abdullah, F., Ward, R., \& Ahmed, E. (2016). Investigating the influence of the most commonly used external variables of TAM on students' Perceived Ease of Use (PEOU) and Perceived Usefulness (PU) of e-portfolios. Computers in Human Behavior, 63, 75-90. https://doi.org/10.1016/ j.chb.2016.05.014

Ajzen, I., \& Fishbein, M. (2005). The influence of attitudes on behavior. In \& M. Z. D. Albarracin, B. Johnson (Ed.), Handbook of attitudes and behavior.

Bonn, M. A., Kim, W. G., Kang, S., \& Cho, M. (2016). Purchasing Wine Online: The Effects of Social
Influence, Perceived Usefulness, Perceived Ease of Use, and Wine Involvement. Journal of Hospitality Marketing and Management, 25(7), 841-869. https://doi.org/10.1080/19368623.2016.1115382

Cheung, R., Vogel, D. (2013). Predicting user acceptance of collaborative technologies: An extension of the technology acceptance model for elearning. In Computers \& Education (63(0), pp. 160-175).

Danurdoro, K., \& Wulandari, D. (2016). The Impact of Perceived Usefulness, Perceived Ease of Use, Subjective Norm, and Experience Toward Student's Intention to Use Internet Banking. Jurnal Ekonomi Dan Ekonomi Studi Pembangunan, 8(1), 17-22. https://doi.org/10.17977/ um002v8i12016p017

Davis, F. D. (1989). Perceived usefulness, perceived ease of use, and user acceptance of information technology. MIS Quarterly: Management Information Systems, 13(3), 319-339. https://doi.org/ $10.2307 / 249008$

Engel, J. F., Blackwell, R. D., \& Miniard, P. W. (1995). consumer behavior (8th ed.). Dryder.

Hansen, J. M., Saridakis, G., \& Benson, V. (2018). Risk, trust, and the interaction of perceived ease of use and behavioral control in predicting consumers' use of social media for transactions. Computers in Human Behavior, 80, 197-206. https://doi.org/10.1016/j.chb.2017.11.010

Indarsin, T., \& Ali, H. (2017). Attitude toward Using m-Commerce: The Analysis of Perceived Usefulness Perceived Ease of Use, and Perceived Trust: Case Study in Ikens Wholesale Trade, Jakarta - Indonesia. Saudi Journal of Business and Management Studies, Vol-2,(Iss-11 (Nov, 2017)), pp: 995-1007. https://doi.org/10.21276/ sjbms.2017.2.11.7

Indiana Malia. (2019). Sebesar 77 Persen Masyarakat Indonesia Pilih Transaksi Cashless. Idn Times. https://www.idntimes.com/business/finance/indi anamalia/sebesar-77-persen-masyarakatindonesia-pilih-transaksi-cashless/full

Kuo, Y. F., \& Y. S. N. (2009). Towards an understanding of the behavior intention to use $3 \mathrm{G}$ mobile value-added services. In Computers in Human Behavior (25(1), pp. 103-110).

Lau, M. M., Lam, A. Y. C., Cheung, R., \& Leung, T. F. (2019). Understanding determinants of customer behavioral intention in using mobile payment at convenience stores. ACM International Conference Proceeding Series, 357-362. https://doi.org/10.1145/3306500.3306549. 
Lee, W., Tyrrell, T., \& Erdem, M. (2013). Exploring the behavioral aspects of adopting technology: Meeting planners' use of social network media and the impact of perceived critical mass. Journal of Hospitality and Tourism Technology, 4(1), 622. https://doi.org/10.1108/17579881311302329

Lim, Y. J., Osman, A., Salahuddin, S. N., Romle, A. R., \& Abdullah, S. (2016). Factors Influencing Online Shopping Behavior: The Mediating Role of Purchase Intention. Procedia Economics and Finance, 35(October 2015), 401-410. https://doi. org/10.1016/s2212-5671(16)00050-2

Marzuki, M. I. I., Rosly, A. N., Roslan, N. S., Abdullah, D., Kamal, S. B. M., \& Azmi, A. (2016). The Role of Perceived Interactivity, Perceived Ease of Use, Perceived Usefulness, and Perceived Enjoyment toward Intention to Use Online Mapping Service Applications. International Academic Research Journal of Business and Technology, 2(2), 135-139.

Moslehpour, M., Pham, V. K., Wong, W. K., \& Bilgiçli, I. (2018). e-purchase intention of Taiwanese consumers: Sustainable mediation of perceived usefulness and perceived ease of use. Sustainability (Switzerland), 10(1). https://doi. org/10.3390/su10010234.

Nikou, S. A., \& Economides, A. A. (2017). MobileBased Assessment: Integrating acceptance and motivational factors into a combined model of Self-Determination Theory and Technology Acceptance. Computers in Human Behavior, 68, 83-95. https://doi.org/10.1016/j.chb.2016.11.020

Park, N., Rhoads, M., Hou, J., \& Lee, K. M. (2014). Understanding the acceptance of teleconferencing systems among employees: An extension of the technology acceptance model. Computers in Human Behavior, 39, 118-127. https://doi.org/ 10.1016/j.chb.2014.05.048

Salah Uddin, M., \& Yesmin Akhi, A. (2014). E-Wallet System for Bangladesh an Electronic Payment System. International Journal of Modeling and Optimization, 4(3), 216-219. https://doi.org/ 10.7763/ijmo.2014.v4.376

Sugiyono. (2011). Pengertian populasi dan sampel dalam penelitian. https://sugithewae.wordpress. com/2012/11/13/pengertian-populasi-dan-sampel-dalam-penelitian/

Wu, B., \& Chen, X. (2017). Continuance intention to use MOOCs: Integrating the technology acceptance model (TAM) and task technology fit (TTF) model. Computers in Human Behavior, 67, 221232. https://doi.org/10.1016/j.chb.2016.10.028

Zeithaml, V.A., Berry, L.L., Parasuraman, A. (1996). The behavior consequences of service quality: Vol. 60 (2). J. Mark. 